\title{
Designing an Itinerant Science Museum
}

\author{
Uriel H. Hernandez-Belmonte, Diana E. Martinez-Rodriguez, and Victor \\ Ayala-Ramirez \\ Universidad de Guanajuato DICIS \\ División de Ingenierías, Campus Irapuato- Salamanca DICIS \\ Carr. Salamanca-Valle Km. 3.5+1.8, Palo Blanco \\ 36700 Salamanca, Mexico \\ \{hailehb, demr\}@laviria.org, \{ayalav\}@ugto.mx
}

\begin{abstract}
In this paper, we present the main activities of the development process of an itinerant science museum. We have developed applications for three target platforms: portable computers, mobile devices and web accessible applications. The selection of these platforms enable the museum to be highly transportable (even in a set of backpacks). The applications are interactivity rich because they can also use hardware sensors, as video cameras and Kinect sensors. The developed applications were already presented to 200 elementary school students with a good appreciation from them as evidenced by the results of an exit survey done in these demonstrations.
\end{abstract}

\section{Introduction}

Museums have important roles in society. One of their most important role is to promote education and culture. Recently, a new kind of museum has emerged, the so called interactive museum. These museums use information technologies intensively. Interactive museums are different to traditional museums because they let the visitors to interact with and to manipulate the elements of the demonstrations. Such an interaction is intended to help the visitor to understand the knowledge content embodied in the demonstration. Interactive museums are complementary to the formal instruction of the visitors. That is particularly interesting because the visitor population covers a broad range of ages. Another advantage of the interactive museum is that the visitor is not restricted to spend a limited time in each stand, he can stay for short or long periods of time.

A study made by Mexico's CONACULTA ${ }^{1}$ reveals that a half of the visitors to Mexican museums possess a higher education degree. The study also shows that these visitors were taken for the first time to a museum in their childhood. Another interesting fact from this study is that less that

\footnotetext{
${ }^{1}$ National Council for Culture and Arts (Spanish: Consejo Nacional para la Cultura y las Artes)
} 
10 percent of the visitors lives outside the most important cities in the country [7]. From there, we can hypothesize that people living in rural locations can not experience a museum visit in their lifetime.

Modern life demands a set of skills for every individual such as the ability to communicate, the capability of solving problems and to be proficient in the use of computers among others. Mexican educational system has the goals of: providing rich instructional materials, to promote scientific computation, to augment the covered population, and to be fair in the possibility of access for all the citizens [5].

Mexican government has also put in its agenda to close the digital divide [3] by providing access to every Mexican citizen to the information and communication technologies. At this moment, Mexico's Telecommunications reform has been approved by the Mexican Congress and it will help to decrease the disadvantage of the poorest population sector. As an example, this reform makes mandatory to provide Internet access to rural communities via satellite.

The purpose of developing an itinerant science museum (ISM) is to be able to visit rural communities to promote science and technology. This will result in an increasing number of people being interested in science. The mobility of the ISM is a key feature to bring scientific demonstrations everywhere. In the literature, we can find previous works on ISMs. For example, the Itinerant Museum of Chemistry History [2], helps people to learn about chemistry by performing experiments. Another example of ISMs is the Astrobiology Road Show proposed by Barge et at. [1], that includes five thematics rooms.

This work presents the design and implementation of an ISM. The proposed museum consists mainly of a set of interactive computer software applications. These applications are deployed in different platforms: portable computers, mobile devices and the Web. The use of these platforms enable the use of applications practically anywhere. The ISM is complemented with some other computer-controlled demonstrations and mobile robotics exhibitions.

Section 2 introduces our approach to ISM, and a description of its main features is given. The details about the ISM development are described in Section 3. In Section 4, the results are shown. Finally, the conclusions are presented in Section 5 . 


\section{Description of the itinerant science museum}

The main goal of the proposed ISM is to attract students to be interested in science, engineering, mathematics and technology [8]. We have not targeted a specific age interval for the audience but our main interest is to reach children and teenagers ( 6-17 years old).

Another key requirement for the ISM is to be portable enough to be able to visit communities under bad access conditions. Difficulty of access can be due to road networks in bad conditions because the lack of maintenance, or even to the lack of a road to get there. Under such conditions, the adaptation of a bus, trailer or any other vehicle is difficult and expensive. We proposed then the approach of ISM in a backpack.

Our ISM proposal covers several subjects: language, mathematics, computer vision, physics and probability topics. Several interactive applications were developed to address these subjects. Each interactive application addresses a learning objective that is implemented using technological tools (computer tools, sensors devices, mobile robots, etc.) For all of them, interactivity is a key feature to engage the user in the learning activity. Several platforms have been used for the deployment of the interactive application: portable computers, mobile devices and web applications. For example, the Web can be a good way to extend the time that the visitors spend using the interactive applications.

\section{$2.1 \quad$ Itinerant demonstrations}

The itinerant science museum can be installed in practically any place in rural communities. A good place to install the ISM is the local elementary school. We set up one exhibition stand for each application to be demonstrated. We use a learning by doing strategy [9]. The children perform some activities in the stand. These activities are intended to provoke learning of some scientific concept and ideas.

Each application stand is composed of several elements (computing platform, applications, sensor, projectors, mobile robots, etc.) All of them are accompanied by a poster with instructions on how to use the application and a paragraph describing the intended learning outcomes.

There is also the help of a person to ease the use of the application and to explain the questions arising from the learning topic. These assistants are trained to deal with such situations. Each application stand has an exclusive area for the users and for the spectators that observe when some other people use the interactive application. 
For each demonstration, we choose a layout taking into account the space constraints and the number of visitors to be served. Figure 1 shows two exemplary layouts. In the case of scholars, the attendants are divided into a number of groups and they follow a pre-defined path in the exhibition layout. Nevertheless, if the available space to set up the ISM is large enough, the attendants could visit the exhibitions without following a fixed sequence. With respect to time constraints, in the guided tour approach, we pre-define a time slot to visit each demonstration in order to let all the students to see the entire exhibition. If there is no time constraints, every visitor could stand at each interactive application as long as he wants. We will pass now to describe the main features of the each type of interactive application.
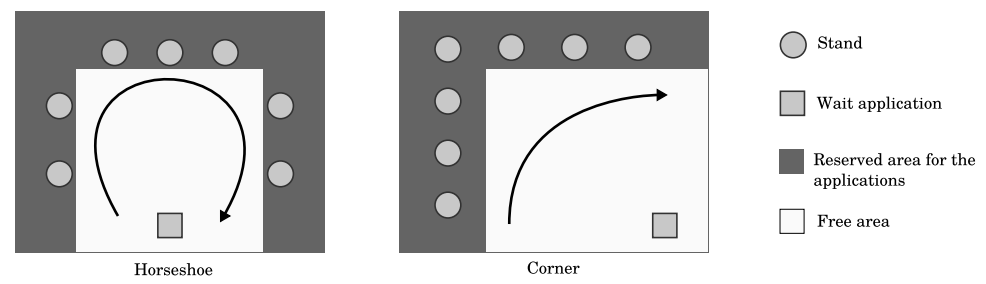

Fig. 1. Examples of the layouts used in the exhibitions.

\subsection{Mobile applications}

There are a number of stands where the interactive application is executed on a mobile device. The visitors can manipulate the elements of the application by using touch gestures. Tablets are very easy to carry and this is very useful to serve a lot of users in the ISMs. The main restriction in mobile devices is the lack of input ports to connect sophisticated sensors and their reduced computing power to execute demanding applications.

\subsection{Computer application}

There are also a number of interactive applications that are suited for both portable and desktop computers. For example, Kinect sensors or camera sensors are designed mostly to work with personal computers. The use of the sensors improve the user experience with regard to the interactivity. Most of the applications developed to use sensors can not be ported directly to mobile devices or to web access.

\subsection{Web applications}

For most of the ISM applications, there is a Web application that can accessed through the Internet. A web site has been designed to host the 
applications of the ISM. However, in the Web applications, the interactivity degree is reduced because of the limitations in available sensors and bandwidth constraints.

\section{Application development process}

In this Section, we describe the software development process carried out for this project. Each application type of the ISM requires both a common set of specifications because the nature of its common purpose, and a particular set of requirements imposed by the target platform.

When an application is targeted for several devices, it has to be developed for several operating systems. That implies to select an adequate scope for each platform given the available resources for development (libraries, programming languages, etc.)

Another issue in target specific applications is the sensor availability. As an example, most mobile devices have a camera, but it is located at a fixed position that may be inappropriate for a computer vision application. A portable or desktop computer have input ports that can be used to connect the camera enabling us to use it in a example, most mobile devices have a camera, but it is located at a fixed position that may be inappropriate for a computer vision application. A portable or desktop computer have input ports that can be used to connect the camera enabling us to use it in a different geometric setup. In the software side, a particular framework can be available only for some operating systems. Moreover, computing power is not the same for each type or target platform. All these issues have to been addressed in order to make appropriate decision choices on the scope of the application for each targeted platform.

The common set of requirements for all the application are: i) The intention of being a tool for learning a concept, ii) the need of being as interactive as possible to engage the user in the learning activity and, iii) to have an attractive interface to capture the interest of the visitor for him to start using it. There requirements are very similar to those for computer video games.

We have used the game development engine Unity for the development of the interactive applications. Unity provides also the capability to handle multi-platform developments. The programming language used for our project was $\mathrm{C \#}$. C\# is an object-oriented programming language that is easy to learn and to adopt for any programmer. The game development engine also supports the integration of $\mathrm{C}$ and $\mathrm{C}++$ artifacts. That is useful for image processing and sensor handling capabilities because 
the related methods perform better in such programming languages. The integration of $\mathrm{C}$ and $\mathrm{C}++$ libraries has only been used for personal computer targets.

The interactive application development model is shown in Figure 2. Firstly, we define the concept to be taught. We develop then a use case for the concept[4]that could incorporate interactive actions between the user and the computing device. The software development process is then executed. We test the application to ensure its reliability and robustness [6]. The last step is to deploy the interactive application in the ISM and to get feedback from the user.

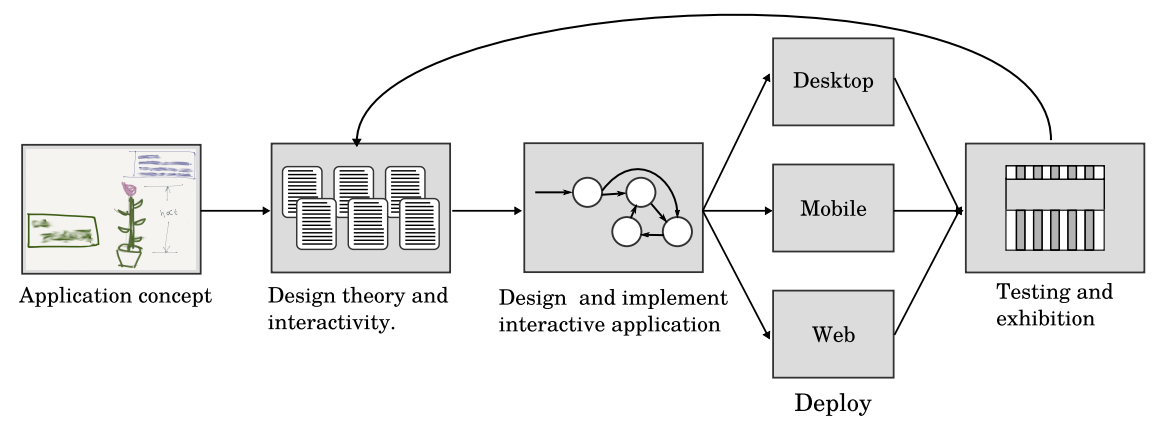

Fig. 2. Interactive application life cycle

\section{Results}

As a result of the development, we have developed eight interactive applications. A summary of these applications is shown in Table 1. We describe there the main features of each application. Some of the applications were developed to use the Kinect sensor ( Word hunter) and several others to include computer vision methods (Virtual Areas and Magic Window). The applications using hardware sensors run both in Windows and Mac OS X operating systems. The full set of eight applications was developed in approximately an eight month period.

Two hundred (200) children have been exposed to the interactive applications of the ISM. We have tested both layout arrangements for the stands presented in the Figure 1 during these exhibitions. We have found that the layout is better for open areas and the horseshoe layout works better for indoor places. The opinions about the interactive applications were good in most cases. Those opinions and observations were recorded in paper-based surveys. In Figure 3, there are some pictures from the 
Table 1. Application summary

\begin{tabular}{|c|c|c|c|c|c|}
\hline Application & Area & Desktop & Mobile & Web & Description \\
\hline Bernoulli Gun & Physics & $\begin{array}{l}\text { Mac OS X, } \\
\text { Windows }\end{array}$ & Android & $\begin{array}{l}\text { Unity Web } \\
\text { Player }\end{array}$ & $\begin{array}{l}\text { It teaches the Bernoulli } \\
\text { principle by controlling a } \\
\text { water flow using a tab. }\end{array}$ \\
\hline Sets & Mathematics & $\begin{array}{l}\text { Mac OS X, } \\
\text { Windows }\end{array}$ & Android & $\begin{array}{l}\text { Unity Web } \\
\text { Player }\end{array}$ & $\begin{array}{c}\text { It teaches the set theory } \\
\text { using. }\end{array}$ \\
\hline Gaussian Bell & Probability & $\begin{array}{l}\text { Mac OS X, } \\
\text { Windows }\end{array}$ & Android & $\begin{array}{l}\text { Unity Web } \\
\text { Player }\end{array}$ & $\begin{array}{c}\text { It teaches about the } \\
\text { origin of the Gaussian } \\
\text { probability density } \\
\text { functions. }\end{array}$ \\
\hline Magic Windows & $\begin{array}{l}\text { Computer } \\
\text { vision }\end{array}$ & $\begin{array}{l}\text { Mac OS X, } \\
\text { Windows }\end{array}$ & $\begin{array}{c}\text { not } \\
\text { supported }\end{array}$ & $\begin{array}{c}\text { not } \\
\text { supported }\end{array}$ & $\begin{array}{c}\text { It teaches how works the } \\
\text { computer vision to } \\
\text { manipulate images. }\end{array}$ \\
\hline Virtual Areas & $\begin{array}{c}\text { Computer } \\
\text { vision, } \\
\text { Mathematics }\end{array}$ & $\begin{array}{l}\text { Mac OS X, } \\
\text { Windows }\end{array}$ & $\begin{array}{c}\text { not } \\
\text { supported }\end{array}$ & $\begin{array}{c}\text { not } \\
\text { supported }\end{array}$ & $\begin{array}{c}\text { It teaches how to } \\
\text { calculate areas by using } \\
\text { simple shapes and a } \\
\text { computer vision interface. }\end{array}$ \\
\hline Word Hunter & language & $\begin{array}{l}\text { Mac OS X, } \\
\text { Windows }\end{array}$ & $\begin{array}{c}\text { not } \\
\text { supported }\end{array}$ & $\begin{array}{c}\text { not } \\
\text { supported }\end{array}$ & $\begin{array}{l}\text { It teaches new vocabulary, } \\
\text { this application uses the } \\
\text { Kinect sensor for the } \\
\text { interactions. }\end{array}$ \\
\hline Gravity & Physics & $\begin{array}{l}\text { Mac OS X, } \\
\text { Windows }\end{array}$ & Android & $\begin{array}{l}\text { Unity Web } \\
\text { Player }\end{array}$ & $\begin{array}{c}\text { It shows how the gravity } \\
\text { works in the Moon, Earth } \\
\text { and Mars. }\end{array}$ \\
\hline Plant & $\begin{array}{l}\text { Biology, } \\
\text { Botanic }\end{array}$ & $\begin{array}{l}\text { Mac OS X, } \\
\text { Windows }\end{array}$ & Android & $\begin{array}{l}\text { Unity Web } \\
\text { Player }\end{array}$ & $\begin{array}{l}\text { It teaches facts about the } \\
\text { parts of the plant. }\end{array}$ \\
\hline
\end{tabular}

exhibitions of the ISM during an itinerant exhibition, and a screen shot of one of the interactive applications.

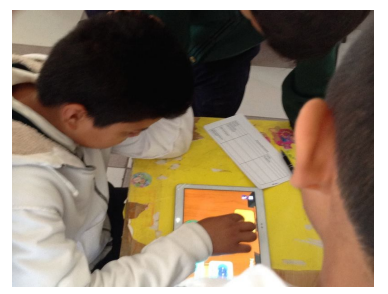

(a) Itinerant exhibition

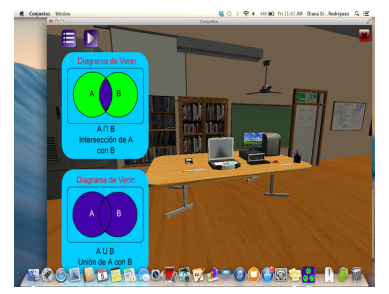

(b) Interactive application (

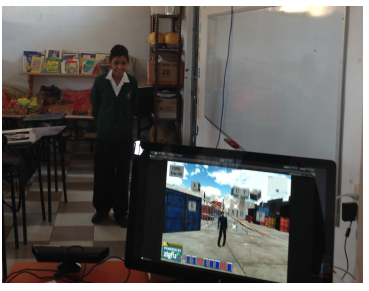

(c) Interactivity using Kinect

Fig. 3. a) Children playing with an interactive application, during and exhibition. b) Desktop interactive application and c) A child playing in the Word Hunter stand.

\section{Discussion and Future Work}

We have presented several aspects of the development of a ISM. The ISM is intended to promote science and technology knowledge and learning in least favored sector of Mexican population. Nevertheless, the applications can be accessed in their website versions from anywhere. In order to amplify the impact of the project in the target audience, we will continue to demonstrate the ISM in some other places. The proposed ISM has shown be a good alternative to catch the interest of new people to the sciences. 
The mobility of the ISM and the way of distributing its applications, increases its coverage. The ISM exhibitions have shown a good acceptance by the people. The layouts proposed for the exhibitions have worked well in indoor and outdoor locations. Future work goals will include to increase the interactivity by improving the human machine interface; and the work towards discovering more engaging ways to learn the concepts behind applications.

\section{Acknowledgements}

The authors gratefully acknowledge to the Mexico's CONACYT (329356/ 229784) for the financial support through the scholarships given by the programs "Convocatoria de Becas Nacionales 2013 Primer Periodo". Also the authors acknowledge to the Universidad de Guanajuato through the project PIFI-2013 and the CONCYTEG-CONACYT FOMIX, through the project GTO-2012- C03-194811, "Aplicaciones Interactivas de la Ciencia y de las Aplicaciones Reales de la Tecnología" EXPLICARTE.

\section{References}

1. Barge, L.M., Pulschen, A.A., Emygdio, A.P.M., Congreve, C., Kishimoto, D.E., Bendia, A.G., de Morais M. Teles, A., DeMarines, J., Stoupin, D.: Life, the universe, and everything: An education outreach proposal to build a traveling astrobiology exhibit. Astrobiology 13(3), 303-308 (2013)

2. Contarini, J.M., Waldman, W.R.: Itinerant museum of chemistry history: The soap. International Journal of Hands-on Science pp. 1646-8937 (2008)

3. Diario Oficial de la Federación: Programa sectorial de educación 2013 2018. http: // www.dof.gob.mx/nota_detalle_popup.php?codigo=5326569 (Accessed September $1,2014)$

4. Eriksson, H.E., Penker, M.: Business Modeling With UML: Business Patterns at Work. John Wiley \& Sons, Inc., New York, NY, USA, 1st edn. (1998)

5. Gobierno de la Republica: Explicación ampliada de la reforma en materia de telecomunicaciones. http://reformas.gob.mx/wp-content/uploads/2014/06/ EXPLICACION_AMPLIADA_DE_LA_REFORMA_EN_MATERIA_DE_TELECOMUNICACIONES. pdf (Accessed September 1, 2014)

6. Humphrey, W.S.: A Discipline for Software Engineering. Addison-Wesley Longman Publishing Co., Inc., Boston, MA, USA, 1st edn. (1995)

7. Navarro, M.C.: Estudio de visitantes a museos 2010. http://sic.conaculta.gob. mx/estudios_publico/17.pdf (Accessed August 25, 2010)

8. Patterson, M., Elliott, J., Niebuhr, D.: A STEM experiment in informal science education: ROVs and AUVs survey shipwrecks from the american revolution. In: Oceans, 2012. pp. 1-8 (Oct 2012)

9. Patterson, M., Haynes, S., Carpenter, L.: Activity: Designing an autonomous underwater vehicle (AUV): Concepts in lift, drag, thrust, energy, power, mass, and buoyancy. Journal of Marine Education vol. 20, 28-35 (2004) 